Int. J. Morphol.,

39(2):371-377, 2021.

\title{
Small Bronchiolar Histopathological Changes Related to Prolonged Diabetes
}

\author{
Pequeños Cambios Histopatológicos Bronquiolares Relacionados con la Diabetes Prolongada
}

Amornrat Chookliang; Passara Lanlua; Apichaya Niyomchan \& Sirinush Sricharoenvej

CHOOKLIANG, A.; LANLUA, P.; NIYOMCHAN, A. \& SRICHAROENVEJ, S. Small bronchiolar histopathological changes related to prolonged diabetes. Int. J. Morphol., 39(2):371-377, 2021.

SUMMARY: Diabetes mellitus increases the risk of developing chronic obstructive pulmonary disease (COPD). The small bronchiole is a prominent site of airflow obstruction that causes increased airway resistance in patients with the COPD. Therefore, the histological and ultrastructural changes in small bronchioles in streptozotocin (STZ)-induced chronic diabetes were determined. Twenty-four weeks after STZ induction, rats were sacrificed, and the right and left lungs were collected for examination by light and electron microscopy. The alterations to the small bronchioles were the same in both lungs of these diabetic rats. The bronchiolar epithelial cells, both ciliated and secretory club cells, showed pyknotic nuclei and damaged cytoplasmic organelles. Increased thickening of the bronchiolar wall occurred in diabetic rats due to smooth muscle layer thickening, inflammatory cell infiltration, and increased numbers of myofibroblasts with collagen deposition. These results indicated that chronic diabetes caused extreme damage to small bronchioles, which may lead to chronic small airway obstruction and ultimately increase the likelihood of COPD progression. This basic knowledge provides a better understanding of the progression of pathogenesis in the small airways of patients with prolonged diabetes.

KEY WORDS: Lung; Small bronchiole; Chronic diabetes; Streptozotocin.

\section{INTRODUCTION}

Diabetes mellitus (DM) is a common comorbidity of chronic obstructive pulmonary disease (COPD). Chronic $\mathrm{DM}$ can worsen the progression and prognosis of COPD via increased inflammation and impaired lung function. In contrast, the inflammatory processes of COPD can be a risk factor for the development of DM (Ho et al., 2017). It is well known that small bronchioles are major sites of airflow limitation in patients with COPD (Baraldo et al., 2012). Small bronchioles control the flow of air to the alveoli and are mainly lined by two epithelial cell types, namely, ciliated and non ciliated club cells (Plopper \& Hyde, 2015). Ciliated cells promote mucociliary clearance, which enables efficient removal of inhaled particles from the lungs (Price \& Sisson, 2019). Secretory club cells, also known as Clara cells, play crucial roles in xenobiotic metabolism and secretory functions involved in modulating inflammatory and immune responses. After airway injury, secretory club cells act as progenitor cells to promote the renewal of nonciliated and ciliated bronchiolar epithelial cells (Rokicki et al., 2016). Moreover, the smooth muscle layer in small bronchioles regulates bronchomotor tone and controls airway caliber (Yan et al., 2018). Alterations to these two main epithelial cells or in smooth muscles can lead to progressive lung damage and impaired lung function. Thus, this study aimed to investigate the effects of streptozotocin (STZ)-induced chronic diabetes on the histological and ultrastructural characteristics of the epithelial and smooth muscle layers of the small bronchioles.

\section{MATERIAL AND METHOD}

Diabetic induction, light (LM) and transmission electron microscopy (TEM). Sixteen Sprague-Dawley male rats (5-8 weeks old, 200-270 g) were used (National Laboratory Animal Center, Mahidol University, Thailand). 
All experimental procedures were approved by the Siriraj Animal Care and Use Protocol, Mahidol University, Thailand (COA No. 008/2561), and performed according to the Guide for the Care and Use of Laboratory Animals. The rats were randomly divided into two groups: the diabetes group $(n=10)$, in which diabetes was induced by an intraperitoneal injection of STZ ( $60 \mathrm{mg} / \mathrm{kg}$ body weight) in citrate buffer ( $\mathrm{pH} 4.5$ ), and the control group $(\mathrm{n}=6)$, which was injected with the buffer alone. All of the rats were sacrificed 24 weeks after diabetes induction to model chronic diabetes (Niyomchan et al., 2019; Baimai et al., 2020).

In the LM, the right lung, including the superior (Rt. Sup.), middle (Rt. Mid.), inferior (Rt. Inf.) and postcaval (Rt. Post-caval) lobes, and one lobe of the left (Lt.) lung (control: $n=3$, DM: $n=4$ ) were fixed in Bouin's solution and processed for histological assessment. The sections ( $5 \mu \mathrm{m}$ thick) were stained with hematoxylin and eosin (H\&E) and Masson's trichrome stain for the measurement of collagen accumulation in the small bronchiolar wall. Fiftysmall bronchioles per group were used to quantify the blue stained collagen fiber deposition in the small bronchiolar wall, which was calculated as the percentage of the collagen fibers in the total area of the small bronchiolar wall at 200x magnification by using the image J software tool (National Institute of Mental Health, Bethesda, Maryland, USA). For TEM imaging, all lobes of both lungs (control: $n=3$, DM: $n=6$ ) were fixed in $2.5 \%$ glutaraldehyde in $0.1 \mathrm{M}$ phosphate buffer solution and prepared for TEM. The ultrastructural changes in the club and ciliated cells in the small bronchioles were observed and photographed under TEM (TECNAI 20, Phillips Electron Optics, Holland) (Niyomchan et al.; Baimai et al.).

Statistical analysis. Data were shown as the means \pm standard deviation. The body weights and collagen accumulations of the rats in the control and diabetic groups were compared by Mann-Whitney U test and independentsamples T-test, respectively (SPSS 18.0 software). Statistical significance was designated as $p<0.05$.

\section{RESULTS}

The diabetic rats showed a significant decrease in body weight compared to the controls $(p<0.05$, control: $405.20 \pm 38.56 \mathrm{~g}$, DM: $239.50 \pm 13.86 \mathrm{~g}$ ), where as the blood glucose levels in the diabetic rats $(421.00 \pm 54.67 \mathrm{mg} / \mathrm{dL})$ were higher than those in the control rats $(138.67 \pm 19.27$ $\mathrm{mg} / \mathrm{dL}$ ). The rats with blood glucose levels higher than 300 $\mathrm{mg} / \mathrm{dL}$ were considered diabetes.
Histological findings. In this study, the small bronchiole characteristics in all lobes of the right and left lungs were similar in each group. Under normal conditions, the small bronchioles were completely lined by simple cuboidal ciliated and nonciliated club cells (Fig. 1A). The club cells were identified by their apical cupola, which protruded into the bronchiolar lumen, and contained basally located nuclei. The ciliated cells displayed cilia on their apical surface. Their concentric nuclei were round or oval in shape (Fig. 1A). The wall of the small bronchiole was lined by a submucosal layer lacking seromucous glands and a layer of circular smooth muscle (Fig. 1A). In the chronic DM group, both the club and ciliated cells contained pyknotic nuclei. Sloughed bronchiolar epithelial cells and cell debris were found in the bronchiolar lumen. In addition, a thickened smooth muscle layer and an abundance of infiltrating inflammatory cells, mainly lymphocytes, were observed in the submucosa of the small bronchioles (Fig. 1B). Furthermore, congestion of blood vessels due to red blood cell accumulation was found in the rats with chronic DM (Figs. 1B, 1D).

With Masson's trichrome staining, collagen fibers were stained blue in marked contrast to the surrounding red tissues. Increased collagen accumulationwas found in the diabetic small bronchiolar walls (Fig. 1D). In addition, the percentage of collagen fibers in the small bronchiolar wall area of all lobes in the right and left lungs was significantly increased in the chronic DM group compared to the control group $(p<0.05$, Rt. Sup., control: $3.27 \pm$ $0.45 \%$; DM: $18.75 \pm 0.75 \%$, Rt. Mid., control: $5.15 \pm$ $0.43 \%$; DM: $21.11 \pm 0.35 \%$, Rt. Inf., control: $4.47 \pm 0.84$ $\%$; DM: $20.07 \pm 0.77 \%$, Rt. Post-caval, control: $3.14 \pm$ $0.39 \%$; DM: $18.08 \pm 0.67 \%$, Lt., control: $4.05 \pm 0.58 \%$; DM: $19.36 \pm 0.94 \%)$. Moreover, there were large elongated myofibroblasts surrounded by an increased amount of collagen fibers in the chronic DM (Fig. 1D).

Ultrastructural observations. In the small bronchiolar epithelium control, the club cells presented with elongated and highly folded nuclei in the basal cytoplasm (Fig. 2A). Smooth endoplasmic reticulum with short tubules and vesicles was found in the apical cytoplasm of the club cells. Spherical, electron-dense secretory granules were apically distributed in the cytoplasm (Fig. 2C). There were many mitochondria with few cristae scattered throughout the club cells (Figs. 2C, 2F, 2G). The Golgi apparatus was situated near the nuclei of the club cells (Fig. 2F). Long rough endoplasmic reticulum (rER) cisternae studded with a small number of ribosomes were observed (Fig. 2G). The ciliated control cells contained round or oval-shaped nuclei with few indentations (Fig. 3A). Numerous polymorphic mitochondria were apparent, mostly in the apical 


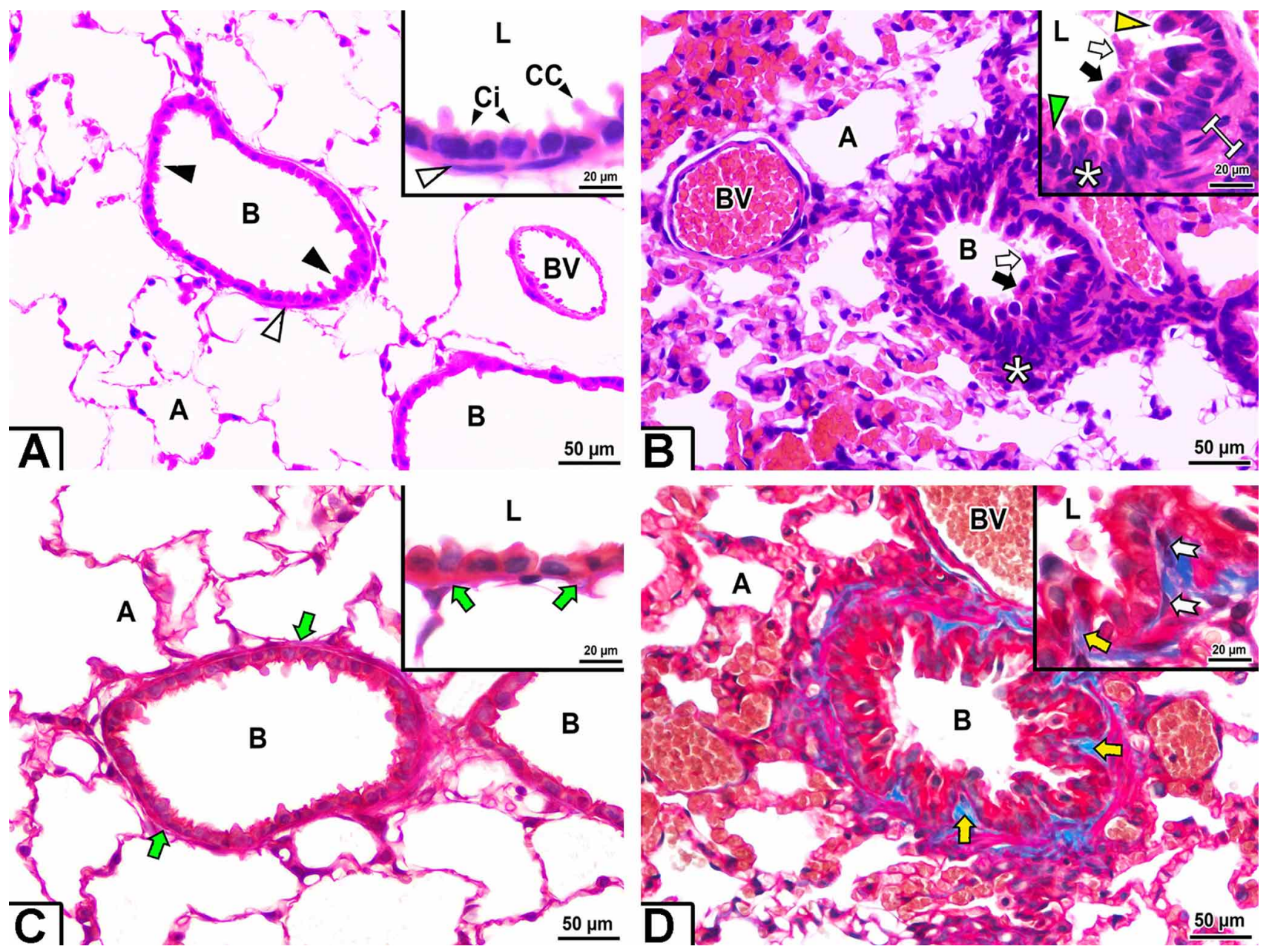

Fig. 1. LM of small bronchioles in control (1A, 1C) and chronic DM (1B, 1D): alveolus (A), blood vessel (BV), bronchiole (B), bronchiolar epithelium (black arrowheads), thin smooth muscle layer (white arrowheads), bronchiolar lumen (L), ciliated cell (Ci), club cell (CC), sloughed epithelial cells (black arrows) and cell debris (white arrows), dark nuclei of club cells (a yellow arrowhead) and dark nuclei of ciliated cells (a green arrowhead), inflammatory cell infiltration (white asterisks), thick smooth muscle layer (white line), collagen fibers (green arrows), increased collagen fibers (yellow arrows), and numerous myofibroblasts (white notched arrows). H\&E (1A-B) and Masson's trichrome (1C-D) stain. 200x. Inset: high magnification of small bronchioles. 600x.

cytoplasm. The apical surface of the ciliated cells was covered with cilia, which were anchored by basal bodies to the apical cytoplasm (Figs. 3A, 3C). The cross-sectioned cilia were enclosed by ciliary membranes and consisted of a circular array of nine outer doublet microtubules and a central pair of singlet microtubules $(9+2)$. Moreover, the outer and inner dynein arms were attached to each doublet microtubule. The radial spokes linked doublet microtubules to a pair of central microtubule complexes (Fig. 3E).

In the chronic DM group, ultrastructural changes in the club and ciliated cells demonstrated severe damage (Fig. 2B). Furthermore, detached cytoplasm of diabetic club cells was found in the bronchiolar lumen (Fig. 2B). Increased heterochromatin clumping in nuclear margination and enlarged mitochondria with damaged cristae and membranes were found in both the club (Figs. 2D, 2E, 2H) and ciliated (Figs. 3B, 3D) cells. In addition, the diabetic club cells extended large apical membrane blebs into the bronchiolar lumen (Fig. 2B). Moreover, separation of the apical membrane bleb from the main portion of the cell was observed in some diabetic club cells (Fig. 2E). These characteristics were suggested as apocrine secretion in the diabetic club cells. Smaller electron-dense and electron-lucent secretory granules (Figs. 2D, 2H), and short rER cisternae (Fig. 2H) were found in the diabetic club cells. Furthermore, severe disruptions to the microtubules and ciliary membranes were observed in cross-sectioned cilia from the diabetic ciliated cells (Fig. 3F). 

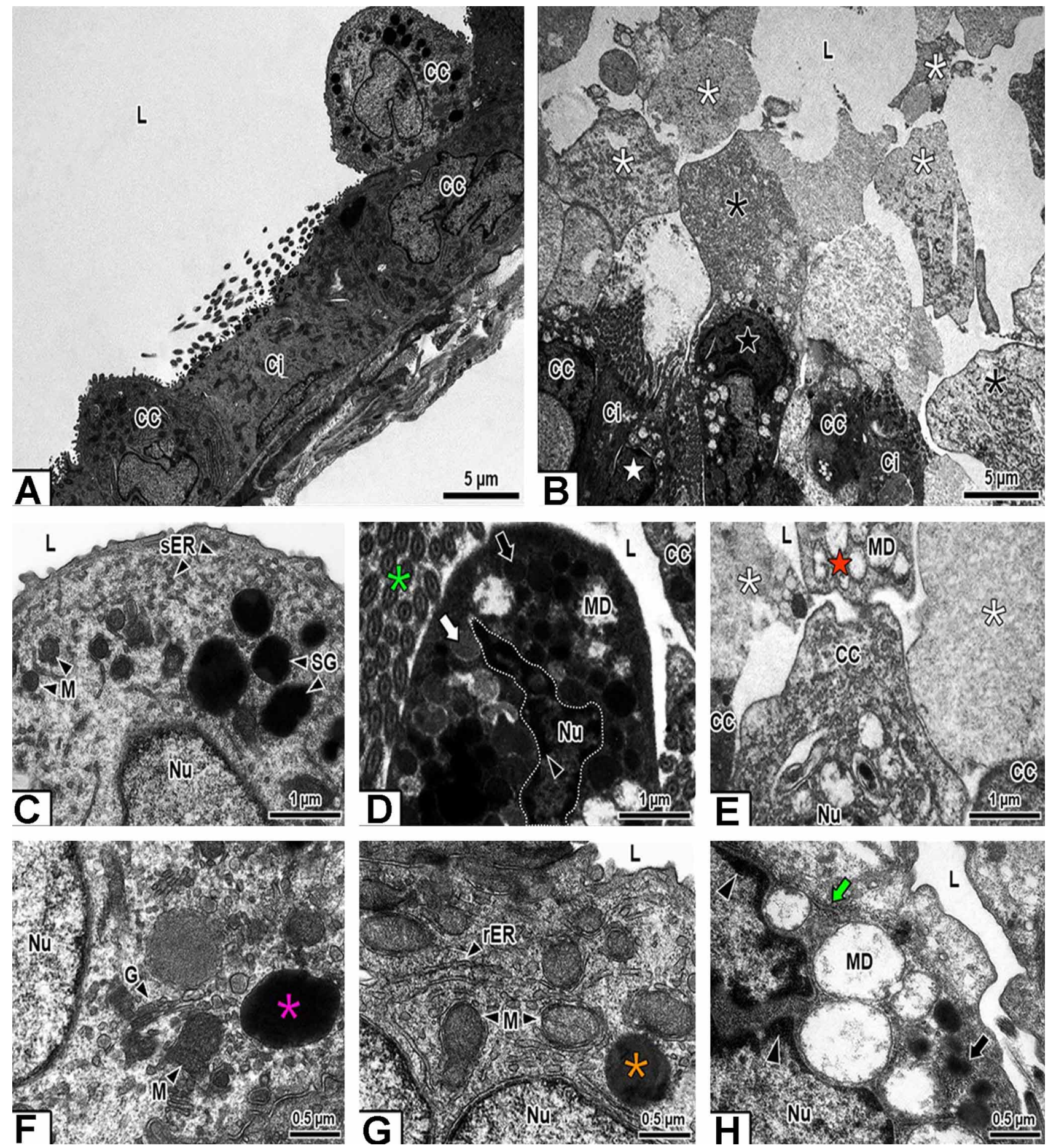

Fig. 2. TEM of small bronchiolar epithelium in control (2A) and chronic DM (2B): bronchiolar lumen (L), ciliated cell (Ci), club cell (CC), detached cytoplasm (white asterisks), damaged club cells (a black star) with apical blebs (black asterisks), and degenerated ciliated cells (a white star). Apical cytoplasm in club cells of control (2C) and chronic DM (2D-E): mitochondria (M), nucleus (Nu), secretory granules (SG), smooth endoplasmic reticulum (sER), chromatin condensation (a black arrowhead), mitochondrial degeneration (MD), small electron-dense (a black arrow) and electron-lucent (a white arrow) secretory granules, cilia of ciliated cell (a green asterisk), and the separation of apical bleb into bronchiolar lumen (a red star). Perinuclear area in club cells of control (2F$\mathrm{G})$ and chronic DM (2H): Golgi apparatus (G), electron-dense (a pink asterisk) and electron-lucent (an orange asterisk) secretory granules, long cisternae of rough endoplasmic reticulum (rER), and short cisternae of rER (a green arrow). 2,200x (2A-B). 10,000x (2C-E). 17,000x (2F-H). 

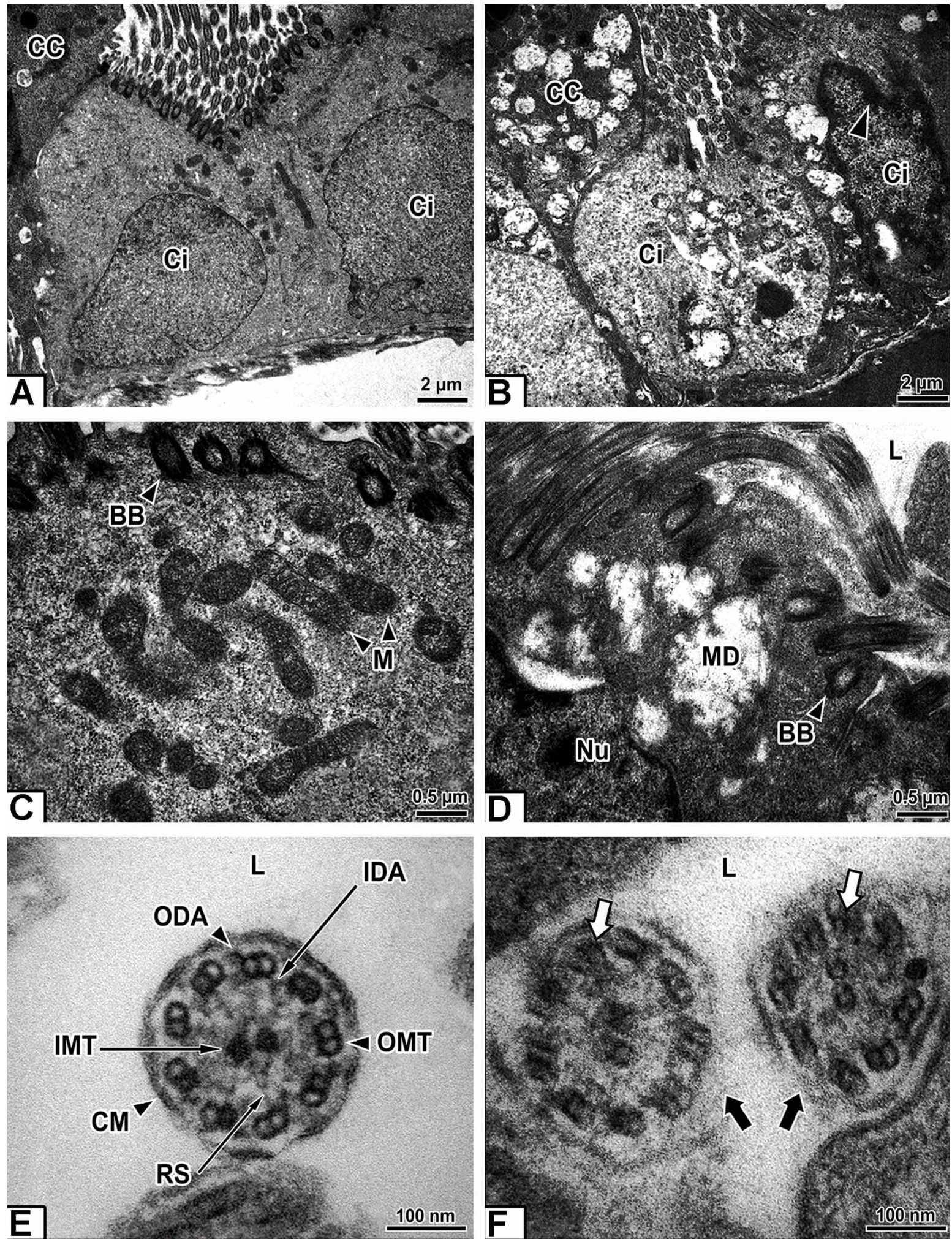

Fig. 3. TEM of ciliated cells in control (3A, 3C) and chronic DM (3B, 3D): ciliated cell (Ci), club cell (CC), chromatin condensation (a black arrowhead), basal body (BB), mitochondria (M), bronchiolar lumen (L), mitochondrial damage (MD), and nucleus (Nu). Cross sections of normal (3E) and diabetic (3F) cilia: ciliary membrane (CM), inner (IDA) and outer (ODA) dynein arms, inner (IMT) and outer (OMT) microtubules, radial spoke (RS), and degenerations of ciliary membranes (black arrows) and microtubules (white arrows). 4,400x (3A-B). 17,000x (3C-D). 135,000x (3E-F). 


\section{DISCUSSION}

During chronic DM, clumped heterochromatin and swollen mitochondria with damaged cristae and membranes were observed in the club and ciliated cells. Moreover, short rER cisternae and disrupted ciliary membranes were found in the club and ciliated cells, respectively. In the polyol pathway, high sorbitol levels induce water influx into both club and ciliated cells. In this pathway, decreased glutathione increases the levels of reactive oxygen species, which promote lipid peroxidation to increase the membrane permeability of the mitochondria and rER. The increased mitochondrial permeability causes intracellular water influx into the mitochondria, resulting in swollen mitochondria in club and ciliated cells (Borza et al., 2013; Shi et al., 2018). Moreover, the release of calcium ions from these organelles activates phospholipases and proteases, which degrade phospholipids and membrane proteins. This result leads to the degeneration of mitochondrial cristae and membranes in club and ciliated cells, shortening of rER cisternae in club cells, and disruption of the ciliary membrane in the cilia of ciliated cells. Furthermore, increased mitochondrial permeability causes the release of cytochrome $\mathrm{C}$, which ultimately activates caspase-3 to induce heterochromatin condensation in cells, as indicated by the observed apoptosis of the club and ciliated cells (Miller \& Zachary, 2017).

In diabetic club cells, extrusion of apical membrane blebs and detachment of cytoplasm into the bronchiolar lumen were found. It has been reported that these characteristics are related to apocrine secretion of club cells (Smith et al., 1974). Peão et al. (1993) found that chronic inflammation is associated with increased merocrine and apocrine secretions of club cells. The club cell secretory protein (CCSP), synthesized by the rER in club cells, functions as an anti-inflammatory agent (Rokicki et al.). Notably, chronic DM induces lung inflammation (Pitocco et al., 2012). Thus, it is possible that chronic DM increases the apocrine secretion of club cells in response to inflammation. On the other hand, the short cisternae of the rER in apoptotic club cells may reduce the synthesis of CCSP, which might cause increased inflammation in chronic DM.

In addition to damaged mitochondria and disrupted ciliary membranes, deteriorated microtubules were found in diabetic ciliated cells; this result may be related to the O-GlcNAcylation of $\alpha$-tubulin, which inhibits $\alpha / \beta$ heterodimerization, possibly causing diminished microtubule formation (Ji et al., 2011). Therefore, the degeneration of microtubules and ciliary membranes leads to abnormal cilia in chronic DM. Mitochondria are sources of ATP for ciliary motility (Price \& Sisson). It is possible that the mitochondrial damage in diabetic ciliated cells caused ATP depletion, which decreased ciliary motility. Therefore, the degeneration of ciliated cells in chronic DM may lead to impaired mucociliary clearance, resulting in susceptibility to respiratory infections in diabetic patients (Yue, 1989). Moreover, epithelial shedding into the bronchiolar lumen was found in chronic DM. Given the level of degeneration observed in diabetic ciliated cells, the accumulation of shed epithelial cells in the bronchiolar lumen may occlude the airway lumen.

In rats with chronic DM, increased lymphocyte accumulation was found in the small bronchiolar wall. In hyperglycemia, the increased adhesion molecules on endothelial cell membranes via advanced glycosylation end products (AGEs) interact with circulating lymphocytes. Moreover, active protein kinase C (PKC) in DM disrupts endothelial tight junctions (TJs). Then, the production of tumor necrosis factor-alpha via the AGE pathway in endothelial cells induces monocyte chemotactic protein-1 expression on bronchiolar epithelial cells, which regulates lymphocyte migration into the small bronchiolar wall through disrupted endothelial TJs in DM (Aronson, 2008; Liu et al., 2018). In addition, smooth muscle thickening occurred in the chronic DM. In diabetes, the activation of PKC stimulates the Ras/Raf-1/MEK-1/ERK1/2 pathways, which activate cyclin D1 to increase smooth muscle cell proliferation, causing a thickening of the smooth muscle layer in chronic DM (Shi et al.; Guo et al., 2020). Additionally, there were increased numbers of myofibroblasts with collagen deposition surrounding the small bronchiole in the chronic diabetes. In DM, the increased expression of transforming growth factor beta1 (TGF- $\beta 1$ ) via the hexosamine pathway in bronchiolar epithelial cells stimulates the differentiation of myofibroblasts, which produce and release collagen type I into the extracellular matrix via the TGF- $\beta 1 / \mathrm{Smad}$ pathway (Evans et al., 2003; Shi et al.). Thus, chronic DM induced fibrosis in the small bronchiolar wall. Ultimately, the thickened smooth muscle layer, inflammatory cell infiltration, and fibrosis in the small bronchiolar wall may promote small airway narrowing and, ultimately, increase airflow resistance in the small conducting airways of patients with chronic DM (Baraldo et al.).

In conclusion, this study suggests that chronic DM directly induces severe structural changes in small bronchioles that may cause narrowing of the bronchiolar lumen and lead to severe small airway obstruction. In the long term, these alterations may increase the risk of developing COPD in diabetic patients. 


\section{ACKNOWLEDGEMENTS}

This study was supported by the Chalermphrakiat Grant, Faculty of Medicine Siriraj Hospital, Mahidol University and the Development and Promotion of Science and Technology Talents Project, the Royal Thai Government, Thailand.

CHOOKLIANG, A.; LANLUA, P.; NIYOMCHAN, A. \& SRICHAROENVEJ, S. Pequeños cambios histopatológicos bronquiolares relacionados con la diabetes prolongada. Int. J. Morphol., 39(2):371-377, 2021.

RESUMEN: La diabetes mellitus aumenta el riesgo de desarrollar enfermedad pulmonar obstructiva crónica (EPOC). El bronquiolo es un sitio prominente de obstrucción del flujo de aire que causa una mayor resistencia de las vías respiratorias en pacientes con EPOC. Por lo tanto, se determinaron los cambios histológicos y ultraestructurales en los bronquiolos en la diabetes crónica inducida por estreptozotocina (STZ). 24 semanas después de la inducción de STZ, se sacrificaron las ratas y se analizaron los pulmones derecho e izquierdo por microscopía óptica y electrónica. Las alteraciones de los pequeños bronquiolos fueron las mismas en ambos pulmones de estas ratas diabéticas. Las células epiteliales bronquiolares, tanto ciliadas como secretoras, mostraban núcleos picnóticos y orgánelos citoplasmáticos dañados. Se produjo un aumento del engrosamiento de la pared bronquiolar en ratas diabéticas debido al engrosamiento de la capa de músculo liso, infiltración de células inflamatorias y un mayor número de miofibroblastos con colágeno. Estos resultados indicaron que la diabetes crónica causaba daño extremo a los pequeños bronquiolos, lo que puede conducir a una obstrucción crónica de las vías respiratorias pequeñas y además aumentar la probabilidad de progresión de la EPOC. Esta información proporcionará un mejor conocimiento de la patogénesis en las vías respiratorias pequeñas de los pacientes con diabetes prolongada.

PAlabras ClaVe: Pulmón; Pequeño bronquiolo; Diabetes crónica; Estreptozotocina.

\section{REFERENCES}

Aronson, D. Hyperglycemia and the pathobiology of diabetic complications. Adv. Cardiol., 45:1-16, 2008.

Baimai, S.; Janta, S.; Lanlua, P.; Chookliang, A.; Niyomchan, A. \& Sricharoenvej, S. Altered oligodendrocytes in spinal enlargements of streptozotocin diabetic rats. Int. J. Morphol., 38(6):1606-13, 2020.

Baraldo, S.; Turato, G. \& Saetta, M. Pathophysiology of the small airways in chronic obstructive pulmonary disease. Respiration, 84(2):89-97, 2012.

Borza, C.; Muntean, D.; Dehelean, C.; Savoiu, G.; Serban, C.; Simu, G.; Andoni, M.; Butur, M. \& Dra gan, S. Oxidative Stress and Lipid Peroxidation - A Lipid Metabolism Dysfunction. IntechOpen, 2013. Available from: Available from: https://www.intechopen.com/books/ lipid-metabolism/oxidative-stress-and-lipid-peroxidation-a-lipidmetabolism-dysfunction
Evans, R. A.; Tian, Y. C.; Steadman, R. \& Phillips, A. O. TGF-beta1mediated fibroblast-myofibroblast terminal differentiation-the role of Smad proteins. Exp. Cell Res., 282(2):90-100, 2003.

Guo, Y. J.; Pan, W. W.; Liu, S. B.; Shen, Z. F.; Xu, Y. \& Hu, L. L. ERK/ MAPK signalling pathway and tumorigenesis. Exp. Ther. Med., 19(3):1997-2007, 2020.

Ho, T. W.; Huang, C. T.; Ruan, S. Y.; Tsai, Y. J.; Lai, F. \& Yu, C. J. Diabetes mellitus in patients with chronic obstructive pulmonary disease-The impact on mortality. PLoS One, 12(4):e0175794, 2017.

Ji, S.; Kang, J. G.; Park, S. Y.; Lee, J.; Oh, Y. J. \& Cho, J. W. OGlcNAcylation of tubulin inhibits its polymerization. Amino Acids, 40(3):809-18, 2011.

Liu, C.; Zhang, X.; Xiang, Y.; Qu, X.; Liu, H.; Liu, C.; Tan, M.; Jiang, J. \& Qin, X. Role of epithelial chemokines in the pathogenesis of airway inflammation in asthma (Review). Mol. Med. Rep., 17(5):6935-41, 2018.

Miller, M. A. \& Zachary, J. F. Mechanisms and Morphology of Cellular Injury, Adaptation, and Death. Pathol. Basis Vet. Dis., 2-43.e19, 2017.

Niyomchan, A.; Sricharoenvej, S.; Lanlua, P. \& Baimai, S. Cerebellar synaptopathy in streptozotocin-induced diabetic rats. Int. J. Morphol., 37(1):28-35, 2019.

Peão, M. N.; Aguas, A. P.; de Sá, C. M. \& Grande, N. R. Anatomy of Clara cell secretion: surface changes observed by scanning electron microscopy. J. Anat., 182(Pt. 3):377-88, 1993.

Pitocco, D.; Fuso, L.; Conte, E. G.; Zaccardi, F.; Condoluci, C.; Scavone, G.; Incalzi, R. A. \& Ghirlanda, G. The diabetic lung--a new target organ? Rev. Diabet. Stud., 9(1):23-35, 2012.

Plopper, C. G. \& Hyde, D. M. Epithelial Cells of the Bronchiole. Comparative Biology of the Normal Lung. 2nd ed. New York, Elsevier, 2015.

Price, M. E. \& Sisson, J. H. Redox regulation of motile cilia in airway disease. Redox Biol., 27:101146, 2019.

Rokicki, W.; Rokicki, M.; Wojtacha, J. \& Dz eljijli, A. The role and importance of club cells (Clara cells) in the pathogenesis of some respiratory diseases. Kardiochir. Torakochirurgia Pol., 13(1):26-30, 2016.

Shi, G. J.; Shi, G. R.; Zhou, J. Y.; Zhang, W. J.; Gao, C. Y.; Jiang, Y. P.; Zi, Z. G.; Zhao, H. H.; Yang, Y. \& Yu, J. Q. Involvement of growth factors in diabetes mellitus and its complications: A general review. Biomed. Pharmacother., 101:510-27, 2018.

Smith, P.; Heath, D. \& Moosavi, H. The Clara cell. Thorax, 29(2):147-63, 1974.

Yan, F.; Gao, H.; Zhao, H.; Bhatia, M. \& Zeng, Y. Roles of airway smooth muscle dysfunction in chronic obstructive pulmonary disease. J. Transl. Med., 16(1):262, 2018.

Yue, W. L. Nasal mucociliary clearance in patients with diabetes mellitus. J. Laryngol. Otol., 103(9):853-5, 1989.

\author{
Corresponding author: \\ SirinushSricharoenvej, Ph.D. \\ Department of Anatomy \\ Faculty of Medicine Siriraj Hospital \\ Mahidol University \\ Bangkok 10700 \\ THAILAND
}

Email: sirinush.sri@mahidol.ac.th

Received: 04-10-2020

Accepted: 30-11-2020 